\section{البصيرة: مبلة الصراهات الإسلامية \\ AL-BASHIRAH: JOURNAL OF ISLAMIC STUIDES \\ Vol. 1 No. 1(2020): 1-20}

Website: https://journal.stiba.ac.id

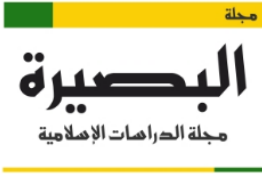

AL-BASHIRAH

\title{
أبو بكر الدمياطي الشافعي \\ التعريف به وبيان منهجه الحديثي في كتابه (إعانة الطالبين)
}

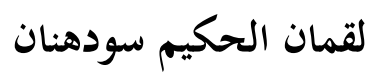

جامعة المللك سعود بالرياض

البريد الإلكتروني: luqmanulhakim81@gmail.com

\begin{abstract}
المستخلص
إن كتاب (إعانة الطالبين على حل ألفاظ فتح المعين) لأبي بكر الدمياطي الشافعي من الكتب الفقهية المهمة في مذهب الشافعي، ودليل ذلك كونه مقررا في المعاهد التقليدية ومرجعا أساسيا للمفتين ومُعتخفا علميا لدى طلبة العلم في بلادنا إندونيسيا. بناء على ذلك يهدف البحث إلى التعرف على أبي بكر الدمياطي الشافعي أحد الأعلام الشافعية، وإبراز شخصيته العلمية في مسار الحديث من خلال دراسة منهجه الحديثي خاصة في كتابه (إعانة الطالبين). اعتمد البحث على المنهج الاستقرائي الاستتاجي. وكان من أظهر نتائجه: أن أبا بكر الدمياطي الشافعي من أبرز العلماء الشافعية

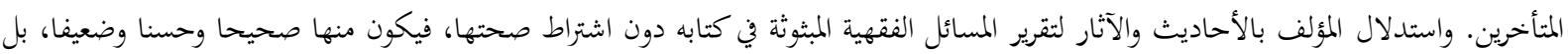
منها ليس لها أصل وعدد يسير موضوع. وبرزت شخصية أبي بكر الدمياطي الحديثية في كتابه (إعانة الطالبين) في نقاط تالية: إكثاره من إيراد

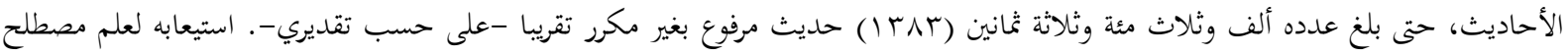
الحديث، وظهر ذلك في كتاب (إعانة الطالبين). ومن مناهج استدلال المؤلف بالحديث عنايته المتميزة بأحاديث الصحيحين في الاستدلال، حتى بلغ عددها - في تقديري- ثلاثة وستون وخمسمئة (بT ه) حديثا تقريبا، وهو عدد متميز، وعدم احتجاجه بالحديث الضعيف والمنكر. الكلمات الدالة: أبو بكر الدمياطي, المذهب الشافعي, إعانة الطالبين, المنهج الحديثي.
\end{abstract}

\section{Abu Bakr al-Dimyāṭi al-Syāfi'ī: Biography and Explanation of His Methodology of Hadith in the Book of I'ānatu al-Țälibīn}

\section{Luqmanul Hakim Sudahnan}

King Saud University, Saudi Arabia

Email: luqmanulhakim81@gmail.com

\begin{abstract}
The book I'aanatu ath-thaalibin 'alaa halli al-faazhi fathi al-mu'iin by Abu Bakr al-Dimyāthi al-Syāfi'i is one of the most important books of figh in the Shafi'i school, the proof is that the book is a reference in local Islamic boarding schools and the main reference for muftis as well as a scientific reference for students in our country, Indonesia. Therefore, this study aimed to identify Abu Bakr al-Dimyathti al-Syafi'i, one of the Shafi'i scholars, and reveal his scientific personality in the science of hadith by studying his method of hadith, particularly in his book I'aanatu ath-thaalibin. This study employed an inductive deductive approach. The results of the research reveal that Abu Bakr al-Dimyathti al-Syafi'i is one of the phenomenal contemporary scholars of the Shafi'i
\end{abstract}

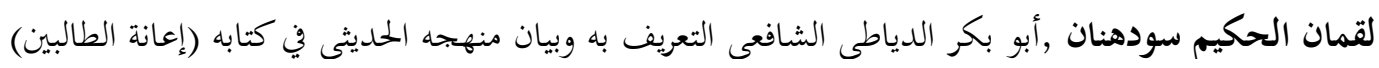




\section{البصيرة: مبلة الصراهات الإملامية \\ AL-BASSHIRAH: JOURNAL OF ISLAMIC STUIDES \\ Vol. 1 No. 1(2020): 1-20}

Website: https://journal.stiba.ac.id

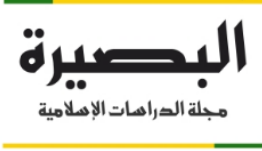

AL-BASHIRAH

school. In his book, he uses a lot of hadiths and atsar as arguments in establishing a law of figh without requiring the validity of these propositions, so that there are arguments that are authentic, fine, and weak. The depth of his knowledge in the field of hadith is evident in his book I'aanatu ath-thaalibin on the following points: the number of hadith cited that he used as the proposition, the number reached approximately one thousand three hundred and eighty-three (1383) hadith marfu' without repetition. His book also shows the depth of his understanding of the science of musthalah al-hadith. Among his method of inference in the hadiths is his excessive attention to the two sahih books in postulating until the number - according to my estimation - reaches around five hundred and sixty-three (563) hadiths, this is a fantastic number, besides he does not postulate weak hadiths and ones that are munkar.

Keywords: Abu Bakr al-Dimyāthi, Shafi'I school, I'aanatu ath-thaalibin, method of hadith.

إنّ الحمد لله نحمده ونستعينه ونستغفره ونعوذ بالله من شرور أنفسنا وسيئات أعمالنا، من يهده الله فلا مضل له ومن يضلل فلا هادي له، وأشهد أن لا إله إلا الله وحده لا شريك له وأشهد أن محمدا عبده ورسوله، أما بعد:

فإن كتاب (إعانة الطالبين على حل ألفاظ فتح المعين) لأبي بكر الدمياطي الشافعي من الكتب الفقهية

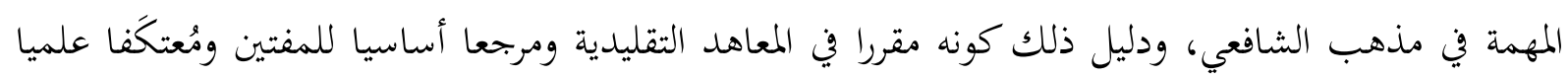
لدى طلبة العلم في بلادنا إندونيسيا.

وبناء عليه، يجدر على طلبة العلم في مذهب الشافعي إلقاء عنايتهم بهذا الكتاب تعلما وتعليما ودراسة،

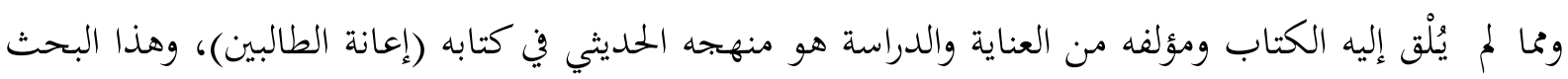
الذي قمت به، قائم لسد هذه الثغرة، فيكون عنوان بحثي (العلامة أبو بكر الدمياطي الشافعي، التعريف به وبيان منهجه الحديثي في كتابه "إعانة الطالبين").

\section{مشكلة البحث:}

ذكر أبو بكر الدمياطي البكري في كتابه (إعانة الطالبين على حل ألفاظ فتح المعين) أحاديث كثيرة لتكون أدلة للمسائل الفقهية التي اشتمل عليها الكتاب، -فبطبيعة الحال- سيسلك منهجا معينا في الاستدلال بالحديث وطريقة إيراده. حدود البحث:

لقمان الحكيم سودهنان ,أبو بكر الدياطى الشافعى التعريف به وبيان منهجه الحديثى في كتابه (إعانة الطالبين) 


\section{البصيرة: مجلة الدراسات الإهلامية AL-BASSHIRAH: JOURNAL OF ISLAMIC STUIDES \\ Vol. 1 No. 1(2020): 1-20}

Website: https://journal.stiba.ac.id

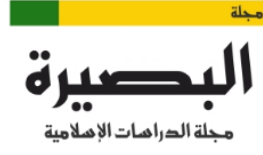

AL-BASHIRAH

يتركز موضوع بحثي في منهج أبي بكر الدمياطي الشافعي الحديثي في كتاب (إعانة الطالبين)، ويتقدمه دراسة مختصرة عن ترجمته.

\section{أسباب اختيار الموضوع:}

أن أبا بكر الدمياطي من أبرز الأئمة الشافعية المتأخرين، حيث ذاعت شهرته عند الشافعية، وعلى وجهه

$$
\text { الخصوص عند البحتمع الإندونيسي. }
$$

أن الكتاب يتبوأ منزلة عالية لدى طلبة العلم في مذهب الشافعي، وعلى وجه الخصوص لدى الشعب

الإندونيسي الذي تمسك بذذا المذهب.

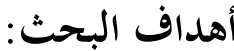

التعرف على العَلم من الأعلام الشافعية، وإبراز شخصيته العلمية في مسار الحديث من خلال دراسة منهجه الحديثي، ورصد شيوخه وتلاميذه وحصر مؤلفاته العلمية. إبراز منهج المؤلف الحديثي من خلال كتابه (إعانة الطالبين)، ومن ثم التوصل إلى معرفة قيمة الكتاب العلمية. تثبيت حجية السنة عند الشافعية من خلال دراسة الكتب الفقهية التي ألفّها الأئمة الشافعية.

\section{المبحث الأول: ترجمة أبي بكر الدمياطي

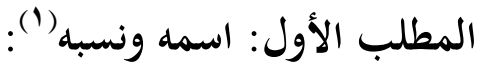

هو أبو بكر بن محمد زين الدين -الشهير بشطا، نسبة إلى الشيخ شطا بدمياط- بن محمود زين الدين بن علي بن محمد بدر الدين بن عبد الله بن إبراهيم بن سليمان بن سالم الحسيني الدمياطي المكي الشافعي، الشهير

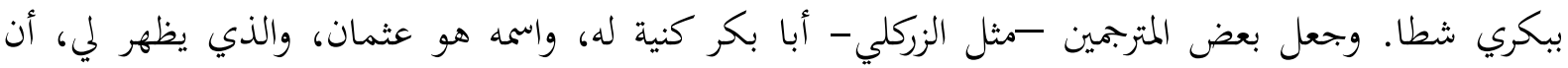

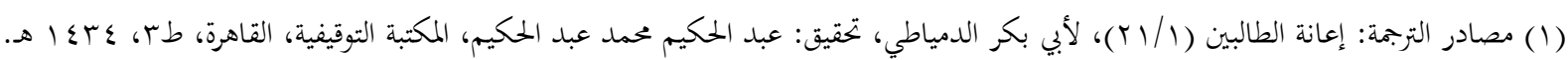

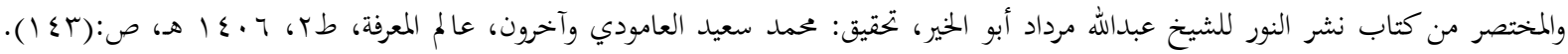

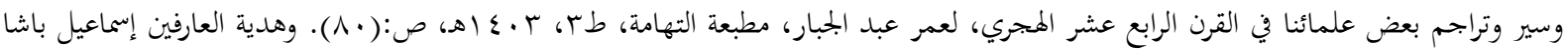

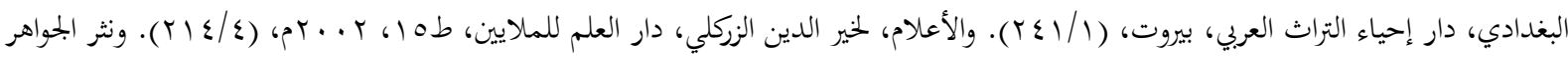

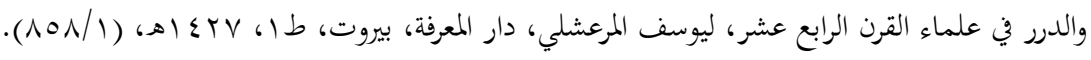
r ب لقمان الحكيم سودهنان , أبو بكر الدياطى الشافعى التعريف به وبيان منهجه الحديثى في كتابه (إعانة الطالبين) 


\section{البصيرة: مجلة الدراهات الإهلاهية AL-BASSHIRAH: JOURNAL OF ISLAMIC STUIDES \\ Vol. 1 No. 1(2020): 1-20}

Website: https://journal.stiba.ac.id

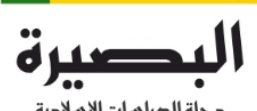

مجلة الصراهات الإهلامية

AL-BASHIRAH

الصواب؛ أبو بكر هو اسم له، كما صرح به المؤلف نفسه في مقدمة كتابه، حيث ذكر اسمه قائلا:"وبعد؛ فيقول

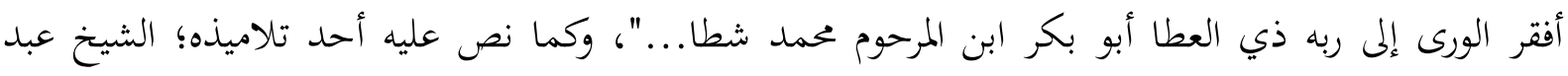

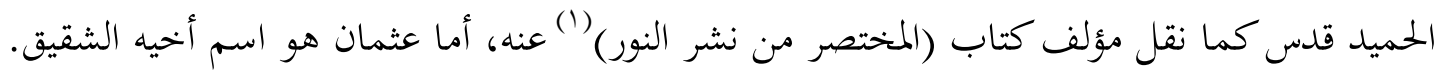

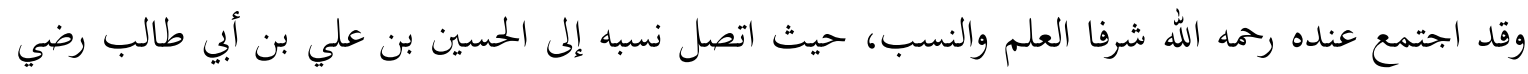
الله عنهما، ومن أجله لقب رحمه الله بالسيد. المطلب الثاني: مولده ونشأته العلمية:

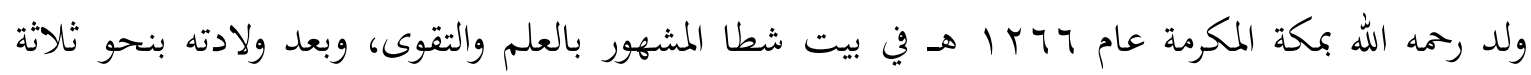

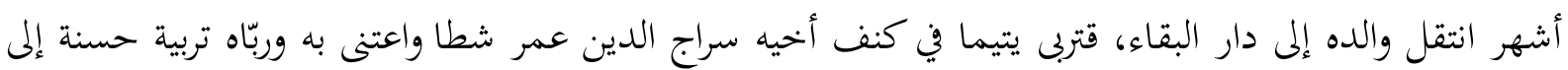

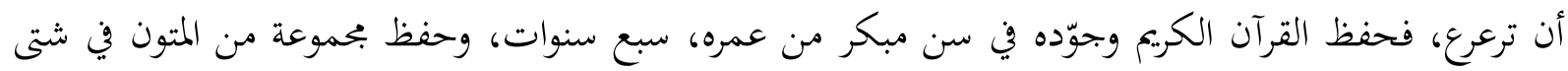

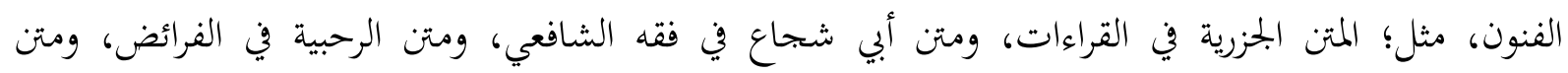

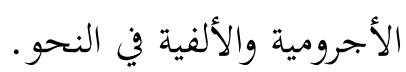

ولا زال أخوه يحثه على طلب العلم، فلازم السيد أحمد زيني دحلان، فتلقى عنه شرح ما حفظه من المتون.

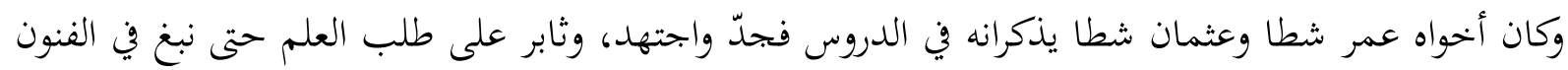

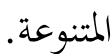

ولما نبغ في الفنون وأتقن في العلوم، تصدى رحمه الله للتدريس بالمسجد الحرم المكي، واشتغل بالتأليف

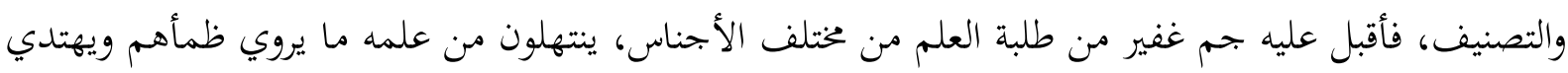

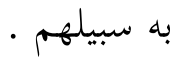

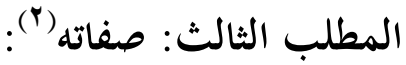
وصفه تلميذه الشيخ عبد الحميد قدس أنه كان وقورا حتشما في الأعين، مهيبا معظما في النفوس محبوبا، ليس للدنيا عنده قدر ولا قيمة، فيعطي منها عطاء جزيلا، ولا يعادي أحدا ولا يخاصم على على الديد الديا.

(1) (1) (1)

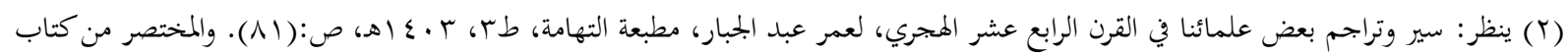

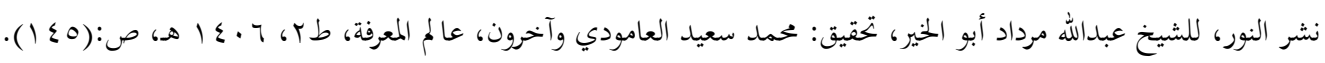
ع لقمان الحكيم سودهنان ,أبو بكر الدياطى الشافعى التعريف به وبيان منهجه الحديثى في كتابه (إعانة الطالبين) 


\section{البصيرة: مجلة الدراهات الإهلاهية AL-BASSHIRAH: JOURNAL OF ISLAMIC STUIDES \\ Vol. 1 No. 1(2020): 1-20}

Website: https://journal.stiba.ac.id

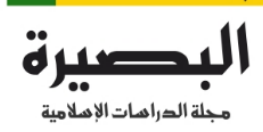

AL-BASHIRAH

أما مكارم الأخلاق، فكان رحمه الله متمتعا بالحلم والصفح والتواضع والقناعة وشرف النفس وكظم الغيظ وحسن الاعتقاد والانبساط مع الجليل والحقير، كل ذلك سجية وطبيعة من غير تكلف لذلك. وكان رحمه الله محافظا على أوقاته، فلا يضيعها في اللهو والسدى، حيث وزعها بين التدريس والتألف وإكثار العبادة، مثل: صلاة النوافل سيما التهجد، وإكثار الصالة على النبي صلى الله عليه وسلم، وملازمة أذكار الصباح والمساء، وقراءة القرآن الكريع.

\section{المطلب الرابع: شيوخه وتلاميذه:}

تلقى القرآن منذ نعومة أظفاره على يد أخيه عمر شطا الذي رباه بعد وفاة أبيه تربية حسنة، فحفظ القرآن في سن مبكر، ويعد عمر شطا شيخه الأول، وله تأثير بالغ في بناء الأسس العلمية لديه، خصوصا في حفظ القرآن والمتون في الفنون المتنوعة (1)

ومن كبار شيوخه: هو أبو العباس أحمد بن زيني دحلان المكي الشافعي، العلامة المشارك الصالح، فقيه مكي مؤرخ. ولد بمكة سنة اسT I هـ، وقيل rr I ا هـ، وتولى فيها إفتاء الشافعية، واشتغل بالعلوم والتدريس ، وتوفي

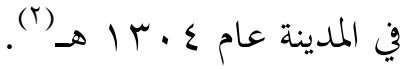
انكب أبو بكر شطا على الشيخ أحمد زيني دحلان، وأول ما تصدر في حلقته عام I V هـ هـ، وانتهل من معين علمه ولازمه وأخذ عنه شروح ما حفظه من المتون، مثل: متن أبي شجاع، ومتن الجزرية، والأجرومية وغيرها. وكان رحمه الله يحب شيخه هذا حبا جما ويجلّه، وتأثر به تأثرا بالغا، ويظهر هذا جليا في كتابه (إعانة الطالبين)، حيث لقبه بالأستاذ علامة الزمان مولانا السيد(r)، وقال في موضع آخر:"مفتي السادة الشافعية، بمكة المحمية، فريد العصر والأوان، مولانا السيد..."(๕)، وله مؤلف لطيف في بيان مناقب شيخه سماه (نفحة الرحمن في بعض مناقب أحمد زيني دحلان).

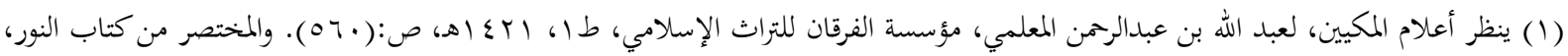

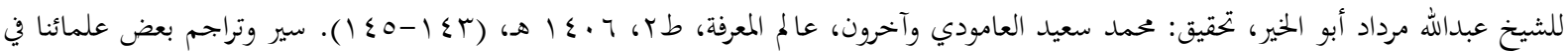

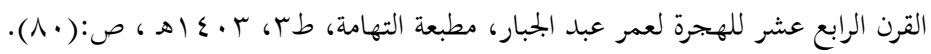

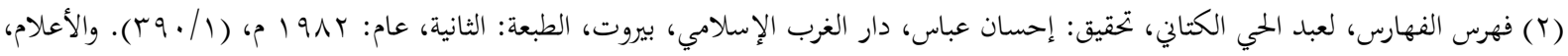

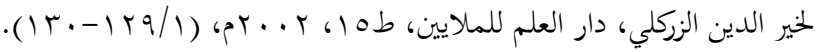

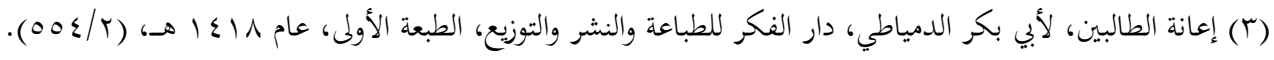

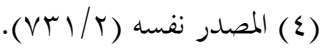

ه لقمان الحكيم سودهنان ,أبو بكر الدياطى الشافعى التعريف به وبيان منهجه الحديثى في كتابه (إعانة الطالبين) 


\section{البصيرة: مبلة الصراهات الإهلامية AL-BASHIRAH: JOURNAL OF ISLAMIC STUIDES \\ Vol. 1 No. 1(2020): 1-20}

Website: https://journal.stiba.ac.id

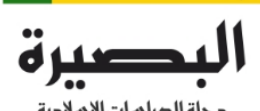

مجلة الصراهات الإهلامية

AL-BASHIRAH

ومن تأثره بشيخه، سرده في كتابه (إعانة الطالبين)(') الدعاء الذي يدعو به الشيخ أحمد بن زيني دحلان

عقيب ختمه القرآن.

\section{تلاميذه (ז)}

حضر في بحلسه عدد هائل من طلاب العلم، وتخرج على يده كثير من العلماء، منهم: - - - ولده؛ أحمد بن أبي بكر شطا.

$$
\text { r - ب الشيخ عبد الحميد قدس الإندونيسي. }
$$

r - الشيخ محمد محفوظ بن الشيخ عبد الله بن عبد المنان الترمسي المكي الفقيه الشافعي.

$$
\text { ع - السيد عبد الله بن عمر بن أحمد باروم. }
$$

ه - - الشيخ أمان الخطيب الفلمباني الإندونيسي.

7 - - الشيخ عبد الله بن أزهري بن عبد الله بن عاشق الدين محمد الفلمباني الإندونيسي.

الشيخ وحي الدين بن عبد الغني بن سعد الله الفلمباني الإندونيسي. V V

المتأمل لهذه القائمة، سيجد أن كثيرا من تلاميذ أبي بكر الدمياطي جاؤوا من إندونيسيا، لعل هذا هو

سر في اشتهار كتاب (إعانة الطالبين) في بلدنا الحبيب إندونيسيا، حيث قام بتدريسه تلاميذه الإندونيسيون في

معاهدهم ومراكزهم العلمية لما عادوا إليها.

المطلب لخامس: مؤلفاته (r).

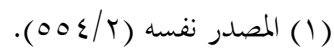

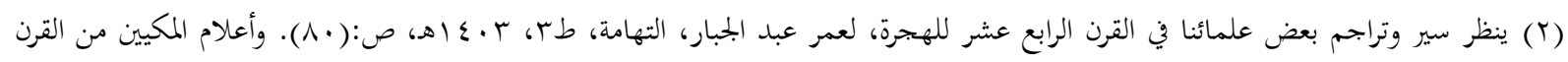

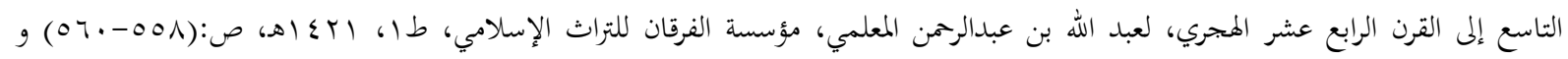

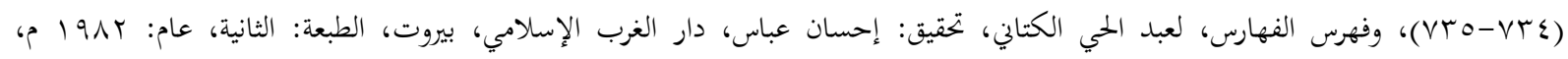

(0. $(0-0 . r / 1)$

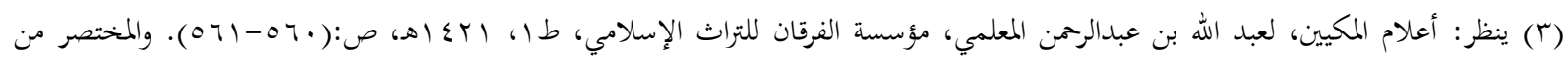

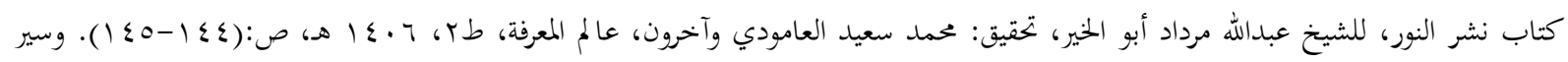
7 


\section{البصيرة: مجلة الدراهات الإهلاهية AL-BASSHIRAH: JOURNAL OF ISLAMIC STUIDES \\ Vol. 1 No. 1(2020): 1-20}

Website: https://journal.stiba.ac.id

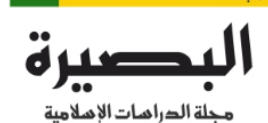

AL-BASHIRAH

كان رحمه الله مشتغلا بالتأليف، وخلف كتبا ومؤلفات جمة، منها: 1 - - إعانة الطالبين على حل ألفاظ فتح المعين. طبع الكتاب في دار إحياء التراث العربي، بيروت، يقع في ع بحلدات، اعتنى به محمد أبو فضل عاشور.

r - - تفسير القرآن العظيم، وصل فيه إلى سورة المؤمنون، ولم أقف عليه مطبوعا. r - - جواز العمل بالقول القديم للإمام الشافعي في صحة الجمعة بأربعة. لم أقف عليه مطبوعا. ع - حاشية على تحفة المحتاج، لم يكملها، وصل فيها إلى باب البيوع، ولم اقف عليه مطبوعا. ه - - حاشية على عمدة الأبرار في أحكام الحج والاعتمار، لم يكملها أيضا، وصل فيها إلى فيه زيارة النبي صلى الله عليه وسلم الأعظم، ولم أقف عليه مطبوعا. 7 - - الدرر البهية فيما يلزم المكلف من العلوم الشرعية. طبع الكتاب في دار ابن حزم، بيروت، بتحقيق ماجد الحموي، ويقع في بحلد لطيف. V - V شروط الجمعة وجواز تعددها بقدر الحاجة في بلد واحدة. لم أقف عليه مطبوعا.

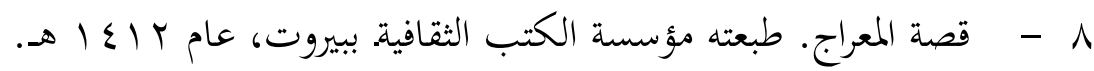
q - القول المبرم في أن منع الأصول والفروع في إرثهم محرم. طبع بهامش الداعي المسموع، للخطيب

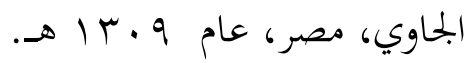

• 1 - القول الْمْنَقَّح المضبوط في صحة التعامل ووجوب الزكاة في ورق النوط. طبعته المكتبة الحسينية

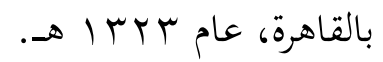

11 Y I - نفحة الرحمن في بعض مناقب أحمد زيني دحلان. طبع في مؤسسة الكتب الثقافية، بيروت.

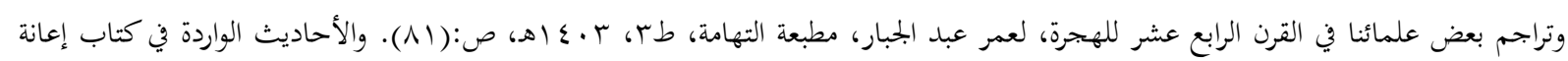

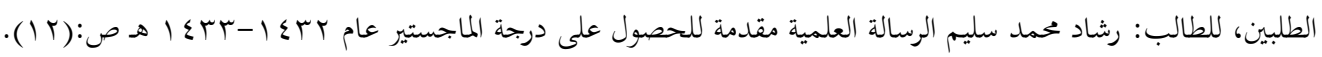
V V Vمان الحكيم سودهنان , أبو بكر الدياطى الشافعى التعريف به وبيان منهجه الحديثى في كتابه (إعانة الطالبين) V 


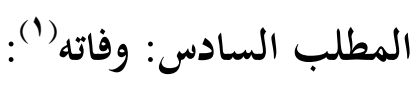

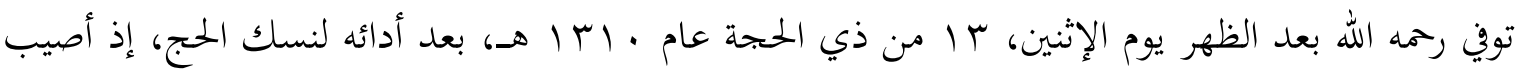
بداء الوباء الذي حدث في تلك السنة. وصلي عليه بعد صلاة العصر عند الكعبة، ثم حمل إلى المعلاة ودفن في اللحد الذي دفن فيه والده وأخوه الشقيق الشيخ عثمان شطا، رمهم الله جميعا وجميع علماء المسلمين وعامتهم. المبحث الثاني: التعريف بالكتاب المطلب الأول: اسم الكتاب وسبب تأليفه (َ):

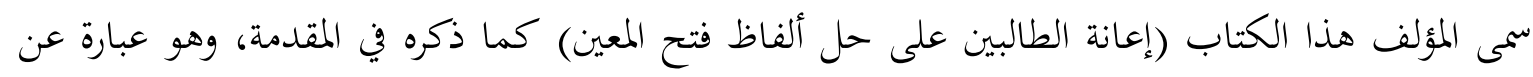

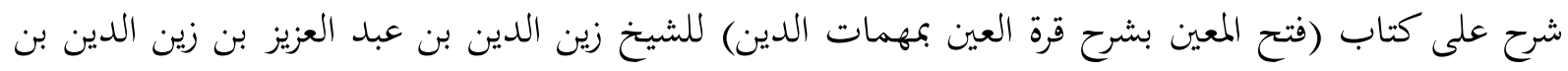

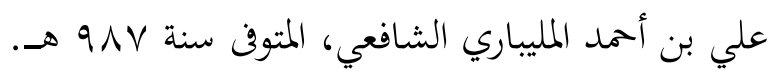

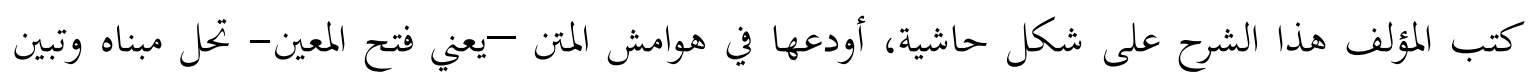

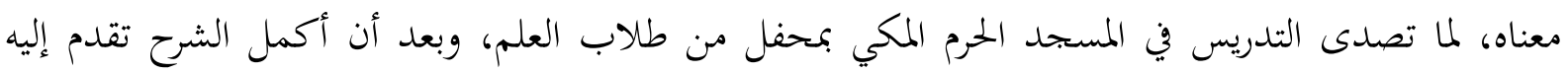

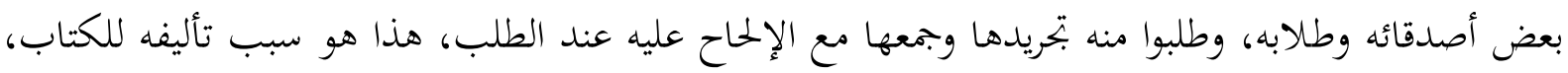

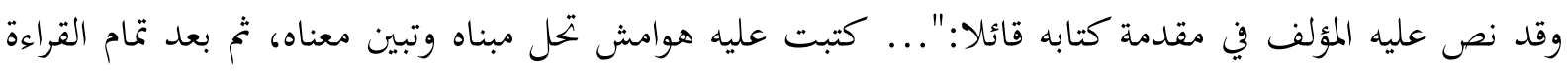

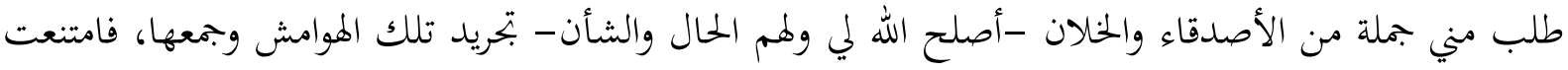

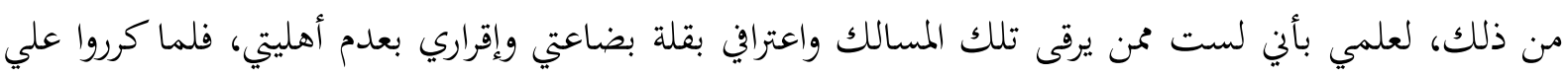

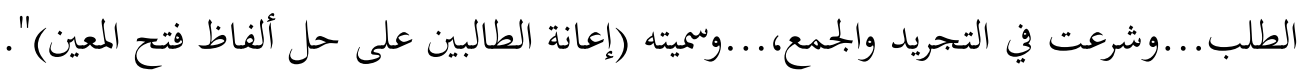
المطلب الثاني: منهجه في التأليف:

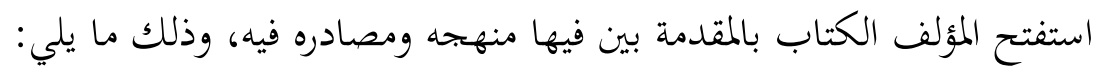

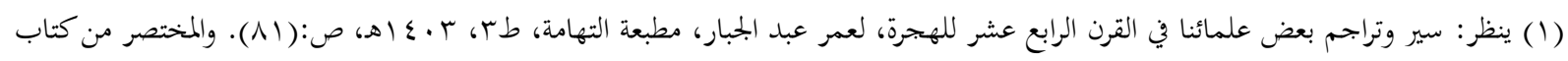

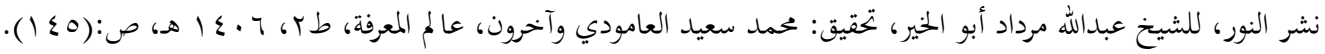

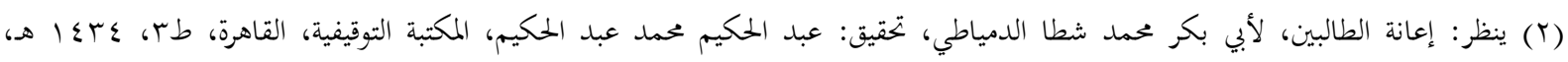
( $(Y-Y) / 1)$ ^ لقمان الحكيم سودهنان , أبو بكر الدياطى الشافعى التعريف به وبيان منهجه الحديثى في كتابه (إعانة الطالبين) 


\section{البصيرة: مجلة الدراسات الإهلاهية AL-BASSHIRAH: JOURNAL OF ISLAMIC STUIDES \\ Vol. 1 No. 1(2020): 1-20}

Website: https://journal.stiba.ac.id

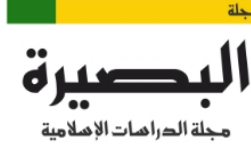

AL-BASHIRAH

\section{JOURNAL OF ISLAMIC STUDIES}

1 - اختطّ المؤلف منهج النقل في التأليف، وبيّن أن مصادره فيه هي الكتب في المذهب الشافعي المتأخرين، مثل:(تحفة المحتاج في شرح المنهاج) لابن حجر الهيتمي، و(فتح الجواد شرح الإرشاد) لأممد بن علي بن محمد بن حجر الهيتمي وإسماعيل بن أبي بكر اليمني، و(هاية المحتاج إلى شرح المنهاج) للرملي، و(حاشية ابن القاسم العبادي على تحفة المحتاج)، و(حواشي البجيرمي)، و وحواشي

$$
\text { الشيخ علي الشبراملسي) وغيرها. }
$$

r - - ترك المؤلف كثرة العزو، وذلك لخوفه من التطويل، يعني به -فيما يظهر لي- عدم التوسع في نسبة الأقوال إلى قائلها.

r - م أنه يتحرى ما حرره الأئمة الشافعية عند الترجيح. المبحث الثالث: منهج أبي بكر الدمياطي الحديثي المطلب الأول: منهجه في الاستدلال بالحديث

بعد تأمل منهج المؤلف في الاستدلال بالحديث، وجدت أنه اختط مسالك عدة فيه، منها: 1 مما لا شك فيه عند الأئمة الأجلاء، أن الصحيحين هما أصح دواوين الإسلام بعد القرآن، وأفما قد احتّلا منزلة عظيمة في الإسلام والمسلمين. فجدير بالمسلمين وعلمائهم العناية بهذين كتابين، بدراستهما وحفظهما واستدلال بأحاديثهما في الأحكام الشرعية.

وقد اعتنى أبو بكر الدمياطي الشافعي عناية بالغة بأحاديثهما في كتابه (إعانة الطالبين)، ، ودليل ذلك: أنه صدّر استدلاله بأحاديث الصحيحين أو أحدهما عند تقرير المسائل الفقهية في كثير من الأحيان، وهذا يدل على عنايته الفائقة بأحاديث الصحيحين أولا، ويدل على حسن الترتيب والتنسيق في التأليف ثانيا، إذ بدأ بأصح الحديث فالأصح عند الاستدلال. عند تتبع عدد أحديث الصحيحين أو أحدها في كتاب (إعانة الطالبين)، وجدت أنه حوى على عدد إنداص هائل من أحاديث الصحيحين أو أحدها، حتى بلغ عددها -من بداية الكتاب إلى ثايته- ثلاثة وستون وخمسمئة (T/0 ) حلديثا تقريبا.

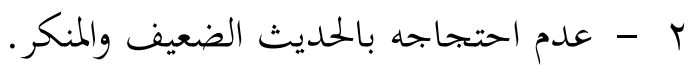




\section{البصيرة: مجلة الدراهات الإهلاهية AL-BASSHIRAH: JOURNAL OF ISLAMIC STUIDES \\ Vol. 1 No. 1(2020): 1-20}

Website: https://journal.stiba.ac.id

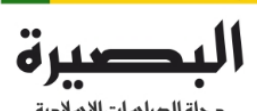

مجلة الصراصات الإهلامية

AL-BASHIRAH

لم يشترط المؤلف رحمه الله في كتابه الاقتصار على الأحاديث المقبولة عند الاستدلال بها، صحيحة كانت

أو حسنة، ولكن وقفت في ثنايا الكتاب على تصريهاته بعدم حجية الحديث الضعيف والمنكر عنده، منها: قوله في بيان حكم كتابة كلمة لا إله إلا الله أو ما شابهها من الأذكار التي فيها أسماء الله في الكفن:"والقول

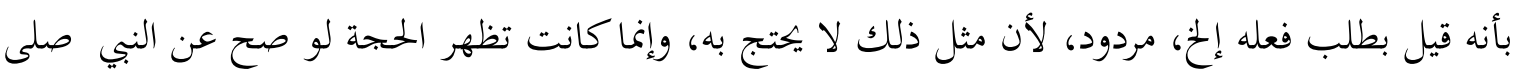
الله عليه وسلم طلب ذلك، وليس كذلك" (1). قوله في سياق بيان قتل السارق بعد سرقته للمرة الرابعة:"(قوله: قتله) أي السارق بعد المرة الرابعة (قوله: أو مؤول) أي وإذاكان غير منسوخ بالفرض، فهو مؤول بأنه عليه السلام إنما قتله بعد المرة الرابعة لكون السارق استحل السرقة (قوله: بل ضعفه إلخ) ما تقدم من الجواب بالنسخ أو التأويل مبني على تسليم أن المروي عنه

صلى الله عليه وسلم صحيح، ثم انتقل عنه إلى الجواب بأن المروي: لا يحتج به لأنه ضعيف أو منكر" (؟). وهذا المنهج هو المنهج الأمثل والأحوط، حيث إن الحديث الضعيف والمنكر لم يثبت أن النبي صلى الله عليه وسلم قال به، والحجة قائمة بما ثبت وروده عن النبي صلى الله عليه وسلم، وهذا أمر مجمع عليه. وقد يعكر على هذا، صنيع المؤلف بإيراد الأحاديث الضعيفة بل الموضوعة في بعض صفحات كتابه، ويجاب على هذا ما يلي: أ - أن موضوع الحديث في فضائل الأعمال، وسيأي بسطه في منهج المؤلف الثالث. ب - أن الحديث صحيح عنده، وضعيف عند غيره. والمقصود من هذه العبارة، أنه لا يتعمد على إيراد الحديث الضعيف والموضوع في كتابه، وإنما ذلك بناء على ترجيحه في حكم الحديث. وأذكر مثالا لهذا الباب، قوله رحمه الله في معرض بيانه عن وقت العقيقة، قال رحمه الله:"ويمتد إلى حين بلوغ، فإذا بلغ سقط الطلب عن الغير، وحسن أن يعق عن نفسه كما مر لخبر أنه صلى الله عليه وسلم:((عَقَّ عَنْ نَفْسِهِ

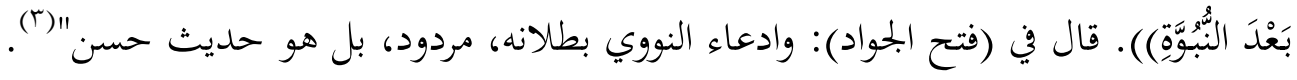
ت -اعتمد المؤلف رحمه الله على منهج النقل في تأليف كتابه (إعانة الطالبين) كما سبق بيانه، وهذا المنهج قد يقتضي وقوع الناقل فيما أخطأ فيه مؤلف الكتاب المنقول منه. ويظهر للباحث أن المؤلف يختط هذا المنهج

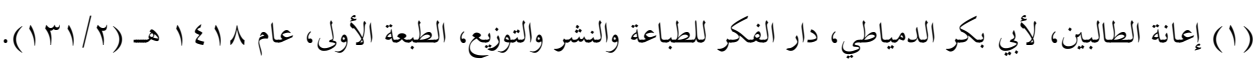

$$
\begin{aligned}
& \text { (T) المصدر نفسه (ع/ع (1)). }
\end{aligned}
$$

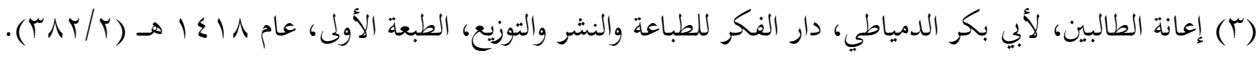
• 1 إلقمان الحكيم سودهنان , أبو بكر الدياطى الشافعى التعريف به وبيان منهجه الحديثى في كتابه (إعانة الطالبين) 


\section{البصيرة: مجلة الدراهات الإهلاهية AL-BASSHIRAH: JOURNAL OF ISLAMIC STUIDES \\ Vol. 1 No. 1(2020): 1-20}

Website: https://journal.stiba.ac.id

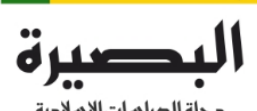

مجلة الصراصات الإصلامية

AL-BASHIRAH

في غالب كتابه حتى في حكمه على بعض الأحاديث، حيث اكتفى بالنقل، دون الرجوع إلى مصادرها

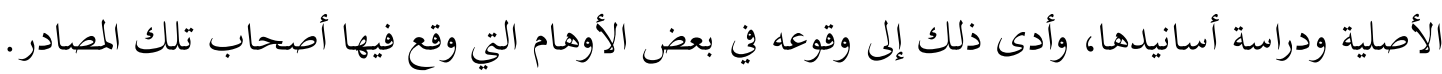

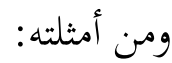

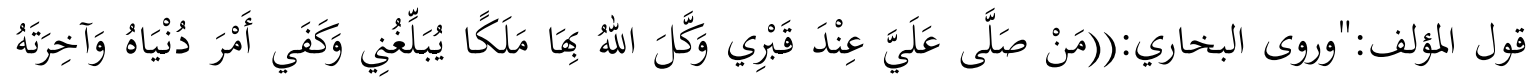

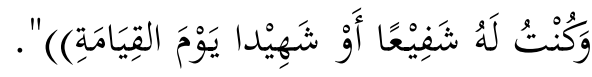

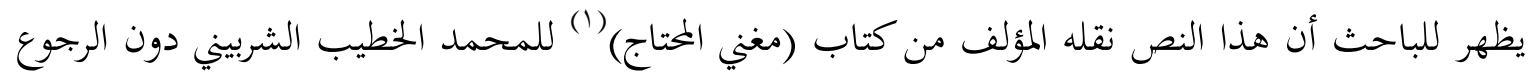

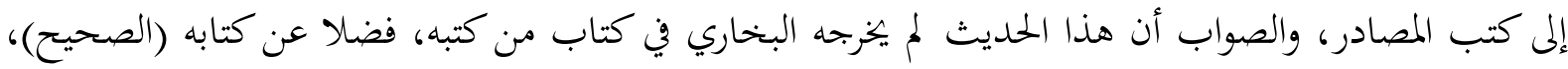
وسيأتي تخريجه في الحديث رقم:(r) ( ). r - استدلاله بالحديث الضعيف في فضائل الأعمال.

اختلف العلماء في حكم الاحتجاج بالحديث الضعيف في فضائل الأعمال، وذهب بعضهم إلى جواز الاستدلال بالحديث الضعيف في هذا الباب بشروط، منها:

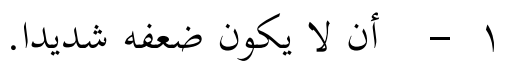

r - - أن يكون أصل العمل الذي ذكر فيه الترغيب والترهيب ثابتا بالدليل الصحيح قرآنا كان أو حديثا.

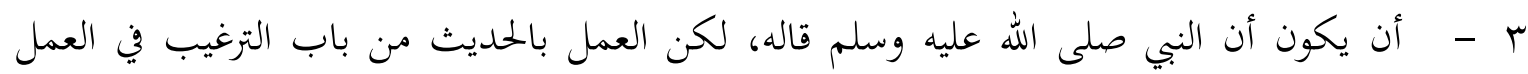

$$
\text { والترهيب عن المعاصي (r). }
$$

وقد صرح المؤلف رممه الله في مواضع من كتابه بانتصار هذا المذهب، وأذكر طرفا من قوله دلالة على مذهبه

قال رمه الله عندما سرد مرويات غسل أعضاء الوضوء:"(قوله: وأما دعاء الأعضاء، إلخ) وهو أن يقول عند

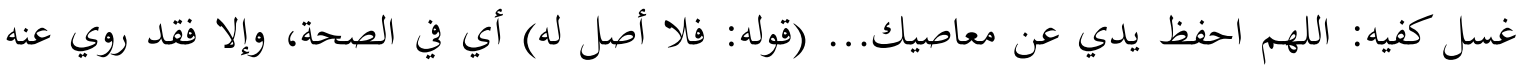
صلى الله عليه وسلم من طرق ضعيفة في (تاريخ ابن حبان) وغيره، ومثله يعمل به في فضائل الأعمال"(").

(Y) ينظر الحديث الضعيف وحكم الاحتجاج به، لعبد الكريم بن عبد الله الخضير، مكتبة المنهاج بالرياض، الطبعة الأولى، عام: هبع إلهـ،

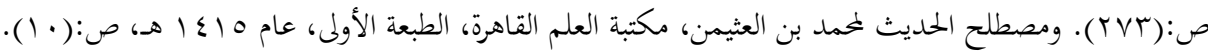

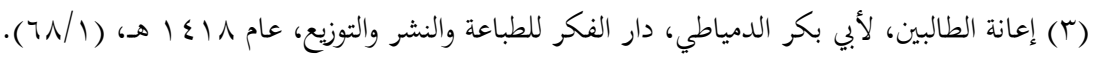
ا 1 لقمان الحكيم سودهنان ,أبو بكر الدياطى الشافعى التعريف به وبيان منهجه الحديثى في كتابه (إعانة الطالبين) 
وقال أيضا في معرض بيان مشروعية صلاة الرغائب، وصلاة ليلة نصف شعبان مئة ركعة:"... واختلف

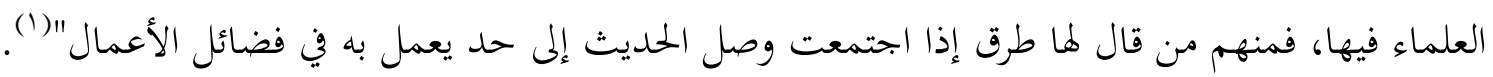

$$
\text { ع - توسعه في سرد الروايات في بعض مسائل. }
$$

المتأمل في كتاب (إعانة الطالبين) سيلاحظ هذا المنهج في بعض مسات مسائل دون بعض، ولعل ذلك له له

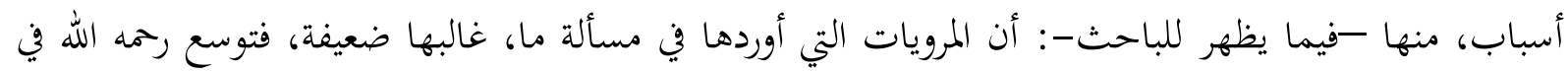

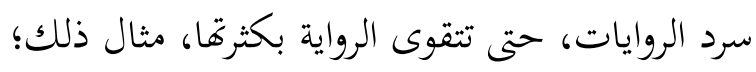

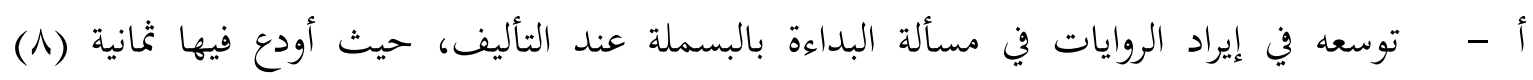
أحاديث. ب - - توسع رممه الله في إيراد الأحاديث التي تحث على الصلاة على البي صلى الله عليه وسلم وفضلها،

$$
\text { حيث أورد فيها ثمانية (م) أحاديث. }
$$

ت - توسعه في إيراد الروايات في مسألة فضل الركن اليماني واستلامه، حيث أورد رممه الله ستة أحاديث

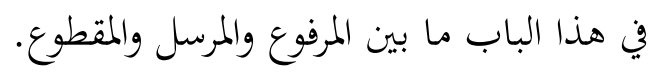
ث - إيراده خمسة أحاديث في بيان فضل زيارة قبر النبي صلى الله عليه وسلم.

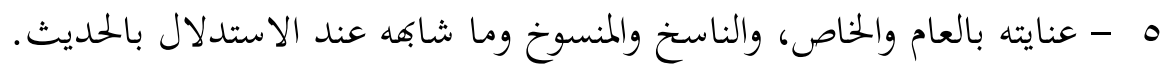

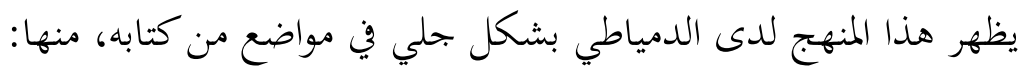

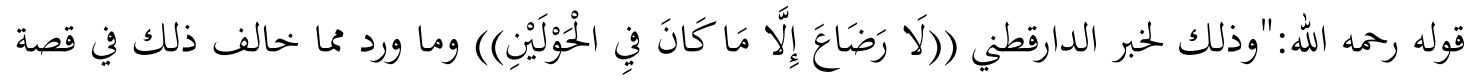

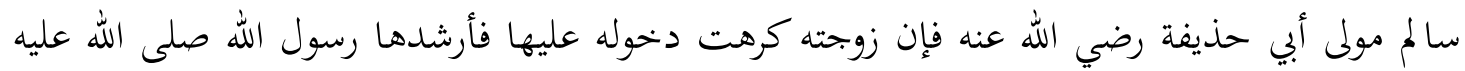

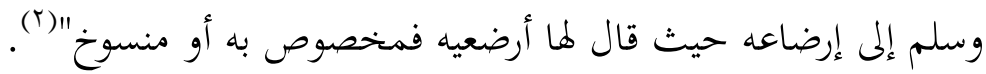

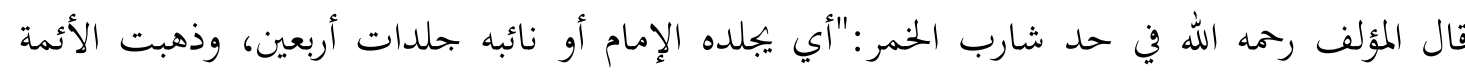

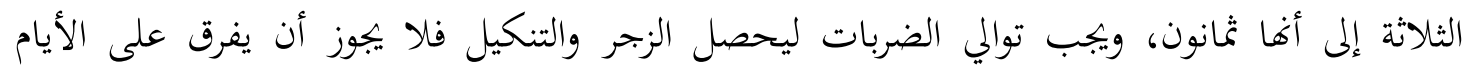




\section{البصيرة: مجلة الدراهات الإهلاهية AL-BASSHIRAH: JOURNAL OF ISLAMIC STUIDES \\ Vol. 1 No. 1(2020): 1-20}

Website: https://journal.stiba.ac.id

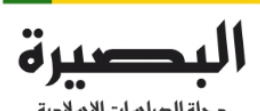

مجلة الصراصات الإصلامية

AL-BASHIRAH

والساعات لعدم حصول الإيلام المقصود من الحدود.... ويكفي الحد المذكور ولو تعدد الشرب مراراكثيرة

قبل الحم، وحديث الأمر بقتل الشارب في المرة الرابعة منسوخ بالإجماع"(1).

قال المؤلف رحمه الله:"وأما خبر النهي عن لحوم الخيل فهو منكر كما قاله الإمام أحمد وغيره أو منسوخ

$$
\text { كما قاله أبو داود". }
$$

هذه النماذج اليسيرة من صنيع المؤلف، أوردةًا في هذا البحث من باب التمثيل لا الحصر، فالمتأمل في

(إعانة الطالبين) سيعثر على نظائرها في مواضع من كتابه. والمتأهل في هذا الباب، سيعينه كثيرا عند ترجيح

الأقوال، إذ المتأهل فيه يتمكن من درء توهم التعارض بين النصوص، فيحل معظم المشاكل المتوهمة في النصوص.

المطلب الثاني: منهجه في إيراد الحديث

إضافة إلى هذا المنهج، فإن للمؤلف منهجا في إيراد الأحاديث عند الاستدلال بها، حيث تم تأمل الأحاديث التي أوردها المؤلف، فوجدته لم يلتزم بمسلك واحد، بل يتنوع مسلكه فيه، ومن هذه المسالك: 1 ومن أمثلة ذلك:

قول المؤلف في معرض بيانه لفضل تلاوة القرآن: قال رسول الله صلى الله عليه وسلم:((أَفْضَلُ عِبَادَةُ أُمَّتي

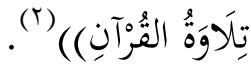

وقوله أيضا في نفس السياق السابق: قال رسول الله صلى الله عليه وسلم:((مَنْ قَرَأَ حَرْفًا مِنْ كِتَابِ اللهِ كُتِبَتْت

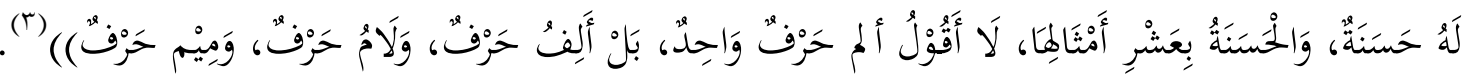
r - تصدير الحديث بقوله:"لما" أو "لخبر"، أو ما يشبهه، وقد يذكر المصدر بعده. ومن أمثلة ذلك:

وقول المؤلف في سياق بيان مشروعية السحور للصائم: لخبر الحاكم في صحيحه:((اسْتَعِينُوا بِطَعَام السَّحَرِ

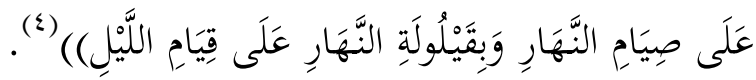

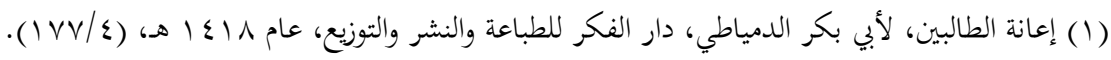

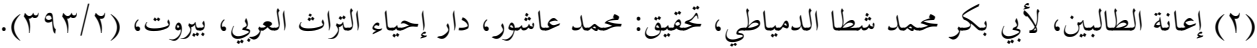

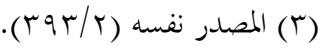

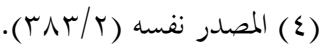

rا 


\section{البصيرة: مجلة الدراسات الإهلاهية AL-BASSHIRAH: JOURNAL OF ISLAMIC STUIDES \\ Vol. 1 No. 1(2020): 1-20}

Website: https://journal.stiba.ac.id

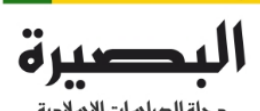

مجلة الصراصات الإصلامية

AL-BASHIRAH

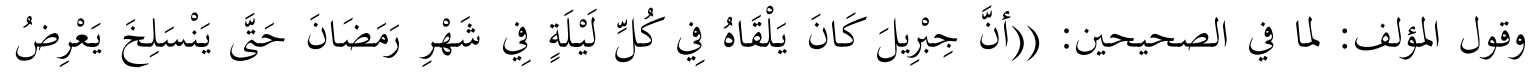

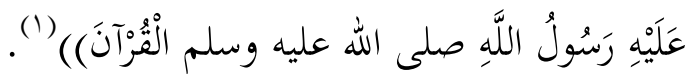

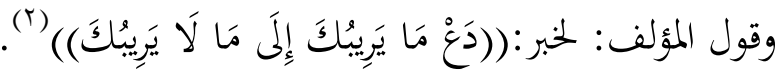

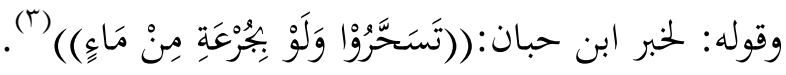

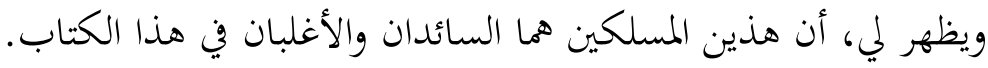

r - يذكر الحكم على الحديث أو الحكم على إسناده، ويذكر متنه.

ومن أمثلة ذلك:

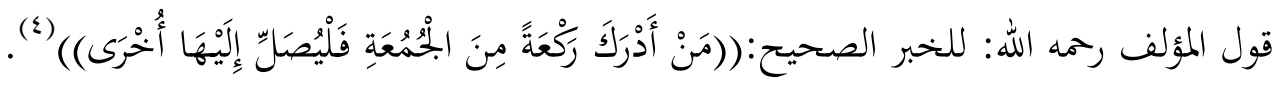

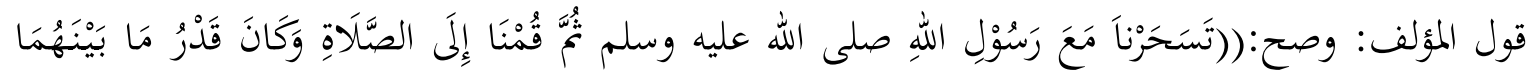

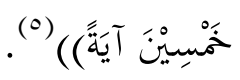

وقوله: ويدل عليه، ما رويناه بالأسانيد الصحيحة في سنن أبي داود، والترمذي، والنسائي، وغيرها من عبد الله

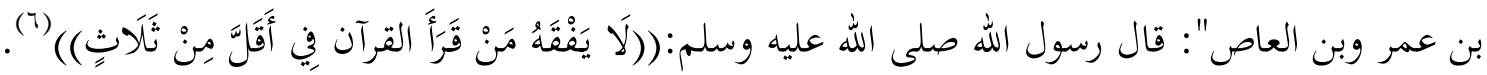

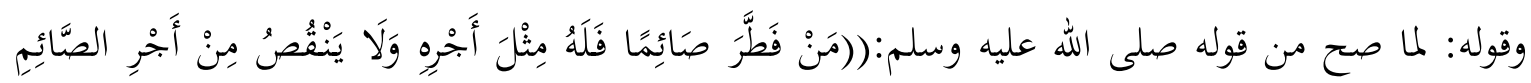

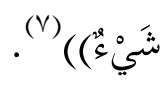

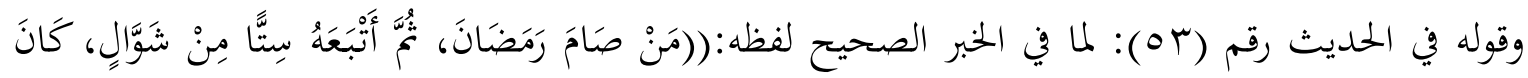

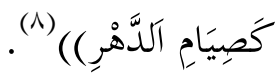

$$
\begin{aligned}
& \text { ع - نقل حكم الحديث عن الأئمة. }
\end{aligned}
$$

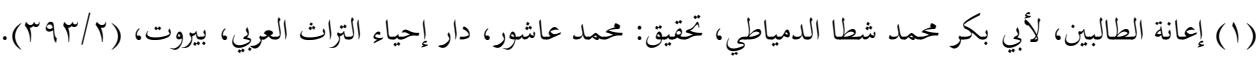

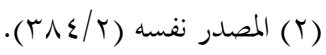

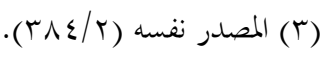

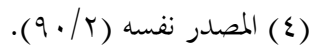

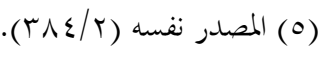

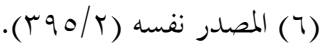

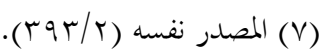

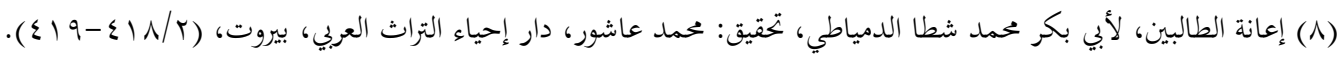

ع ا لقمان الحكيم سودهنان ,أبو بكر الدياطى الشافعى التعريف به وبيان منهجه الحديثى في كتابه (إعانة الطالبين) 


\section{البصيرة: مجلة الدراهات الإهلامية AL-BASSHIRAH: JOURNAL OF ISLAMIC STUIDES \\ Vol. 1 No. 1(2020): 1-20}

Website: https://journal.stiba.ac.id

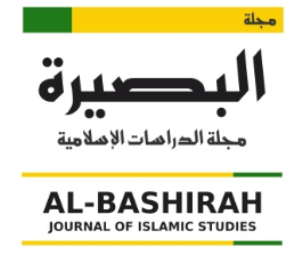

ومن أمثلة ذلك:

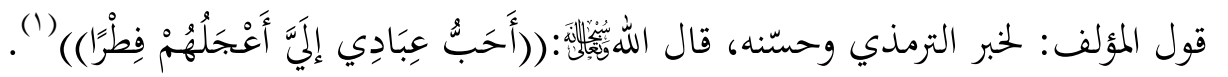
قول المؤلف: (يسن لكل أحد الإدهان غبا) أي وقتا بعد وقت بحسب الحاجة، وذلك لخبر الترمذي وصححه

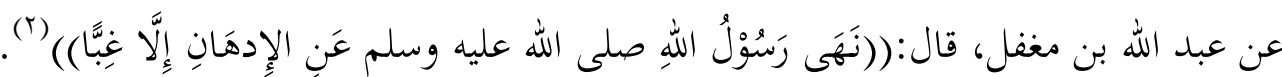

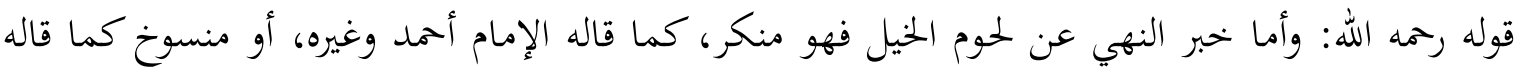
أبو داود (r) قوله: لخبر الترمذي عن ابن عباس رضي الله عنهما وحسنه، قال:((كَانَ لِرسُوْلِ اللهِ صلى الله عليه وسلم

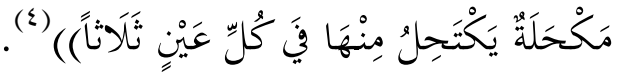
ه - يذكر الصحابي الراوي للحديث، وقد يصحبه بذكر المصدر، ويذكر المتن. ومن أمثلة ذلك:

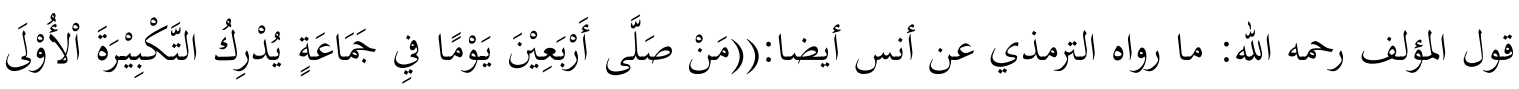

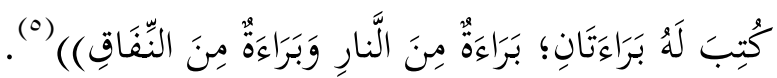

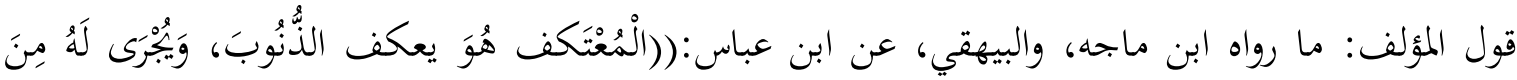

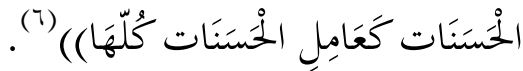

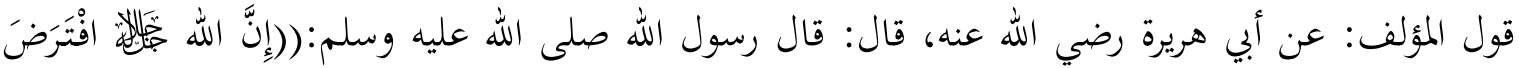

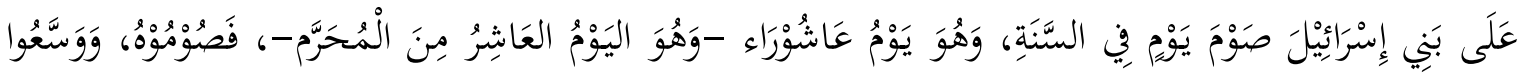

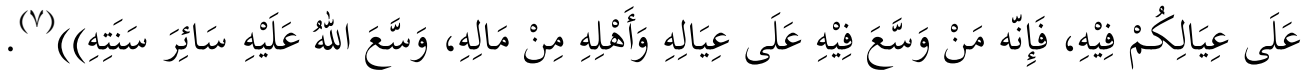
T - بروي الحديث بمعناه.

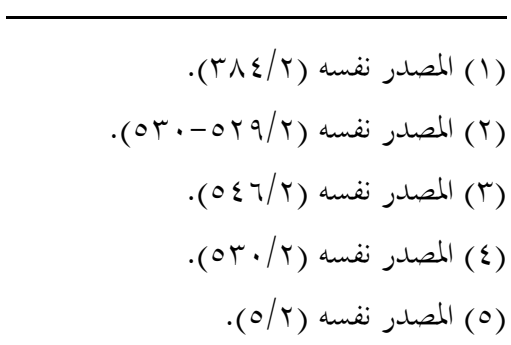
(7) إعانة الطالبين، لأبي بكر محمد شطا الدمياطي، تحقيق: محمد عاشور، دار إحياء التراث العربي، بيروت، (ז/. ع).

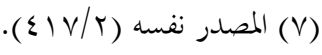
ه 10 لقمان الحكيم سودهنان ,أبو بكر الدياطى الشافعى التعريف به وبيان منهجه الحديثى في كتابه (إعانة الطالبين) 


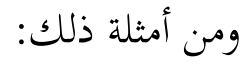
قول المؤلف في معرض بيان وقوف النبي صلى الله عليه وسلم: وذلك لأنه صلى الله عليه وسلم وَقَفَ بَعْدَ النَّوالِ، رواه مسلم (1).

قوله رحمه الله : لأنه صلى الله عليه وسلم وأصحابه سعوا بعد طواف القدوم ولم يعيدوه بعد الإفاضة(T).

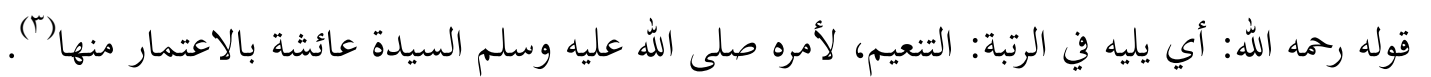

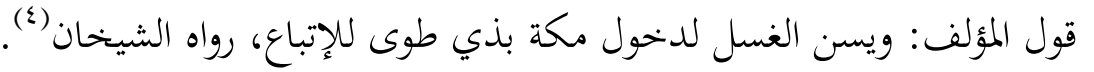

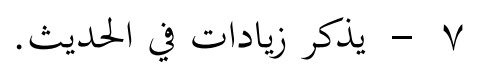

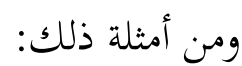

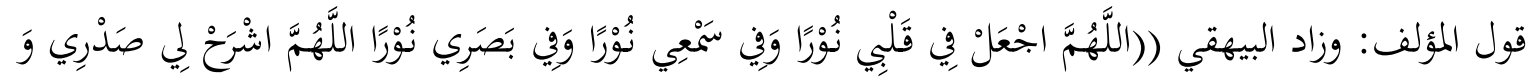

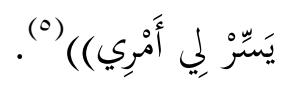

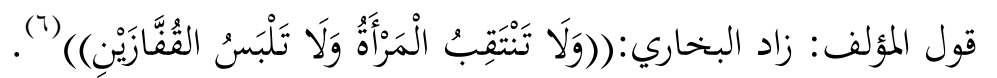

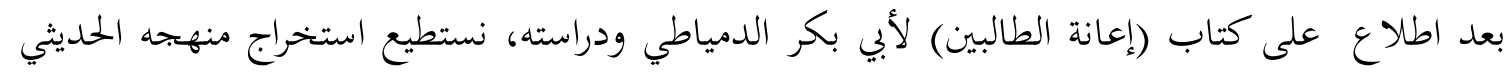

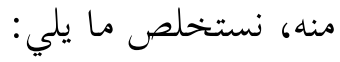
أ - أن أبا بكر الدمياطي يرى حجية السنة، ويظهر هذا جاليا في هذا الكتاب، وقد أكثر من إيراد

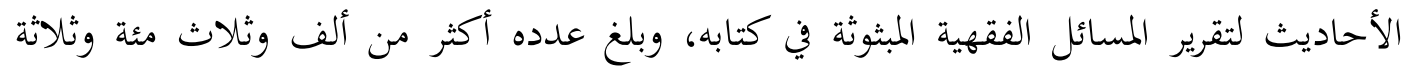

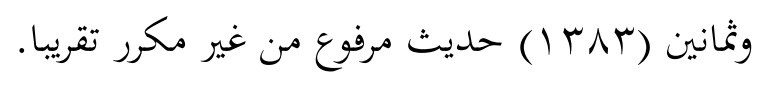

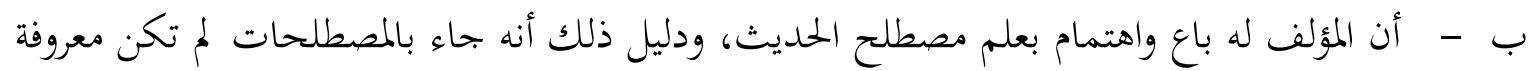

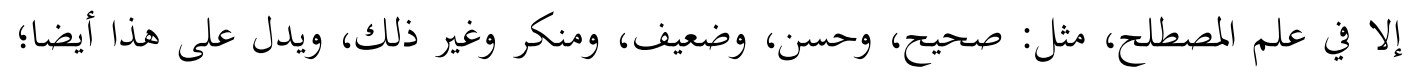

$$
\begin{aligned}
& \text { (1) المصدر نفسه (r/ / § §). }
\end{aligned}
$$

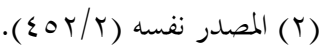

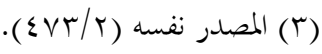

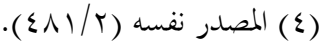

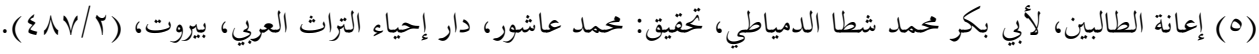

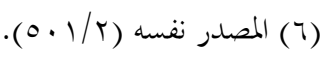

17 القمان الحكيم سودهنان ,أبو بكر الدياطى الشافعى التعريف به وبيان منهجه الحديثى في كتابه (إعانة الطالبين) 


\section{البصيرة: مجلة الدراهات الإهلاهية AL-BASSHIRAH: JOURNAL OF ISLAMIC STUIDES \\ Vol. 1 No. 1(2020): 1-20}

Website: https://journal.stiba.ac.id

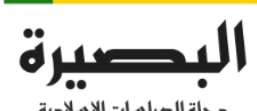

مجلة الصراهات الإهلامية

AL-BASHIRAH

روايته لبعض الأحاديث بالمعنى، وهذا دليل على أنه ملم بموضوع جواز رواية الحمديث بالمعنى عند

$$
\text { بعض المحدثين. }
$$

ت - معرفته بالمصادر الأصلية لكتب الحديث، مثل: صحيح البخاري، وصحيح مسلم، وجامع الترمذي، وسنن النسائي، وسنن أبي داود، وسنن ابن ماجه، والسنن الكبرى للبيهقي، والمستدرك الحاكم،

$$
\text { وصحيح ابن حبان وغيرها، وعزا الأحاديث إليها. }
$$

ث - اطلاعه على أحكام بعض العلماء على الحديث، فينقلها في كتابه.

$$
\text { ج - ويلاحظ عليه ما يلي: }
$$

1 r - - ضعفه في علم علل الحديث ونقده، ودليل ذلك إدراجه لكثير من الأحاديث الباطلة والموضوعة دون بيان حالها، ولكن قد لا يكون هذا عيبا كبيرا له -هي نظري-، إذ لم يبرع كثير من المحدثين في هذا الفن الدقيق إلا نادرا، مثل البخاري، ومسلم، والترمذي، وابن معين، وأحمد، والدارقطني

$$
\text { وغيرهم. }
$$

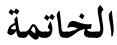

الحمد لله الذي بنعته تتم الصالحات، والصلاة والسلام على خير البريات، وعلى آله وأصحابه ومن تبعهم

$$
\text { بإحسان إلى يوم المعاد، أما بعد: }
$$

فبادئ ذي البادئ، أحمد الله تعالى على توالى مننه وكرمه وتوفيقه، حتى يسر لي في إبحاز هذا البحث

$$
\text { المتواضع، الذي كان من أظهر نتائجه ما يلي: }
$$

1

الشافعي في الحرم المكي، صاحب المؤلفات الجمة، ذاعت شهرته في الآفاق، وتتلمذ بين يديه بعض الطلاب الإندونيسيين، مثل: الشيخ عبد الحميد قدس الإندونيسي، الشيخ محمد محفوظ بن الشيخ

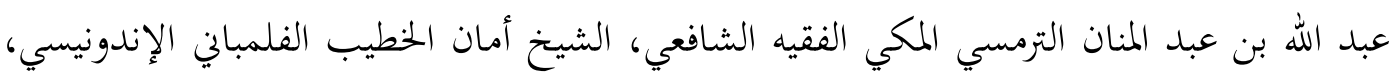
الشيخ عبد الله بن أزهري بن عبد الله بن عاشق الدين محمد الفلمباني الإندونسي، الشيخ وحي الدين بن عبد الغني بن سعد الله الفلمباني الإندونيسي.

لقمان الحكيم سودهنان , أبو بكر الدياطى الشافعى التعريف به وبيان منهجه الحديثى في كتابه (إعانة الطالبين) IV 


\section{البصيرة: مبلة الصراهات الإهلامية AL-BASSHIRAH: JOURNAL OF ISLAMIC STUIDES \\ Vol. 1 No. 1(2020): 1-20}

Website: https://journal.stiba.ac.id

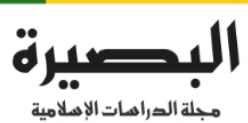

مجلة الصراهات الإهلامية

AL-BASHIRAH

r - كتاب (إعانة الطالبين) -الذي نن في صدد دراسته-، بالحقيقة عبارة عن حاشية، أودعها في هوامش المتن - يعني فتح المعين- تحل مبناه وتبين معناه، لما تصدى التدريس في المسجد الحرم المكي، وبعد أن أكمل الشرح تقدم إليه بعض أصدقائه وطلابه، وطلبوا منه بتريدها وجمعها مع الإلحاح عليه عند الطلب، هذا هو سبب تأليفه للكتاب. r - نص المؤلف في مقدمة كتابه أن منهجه في التأليف هو النقل. ع - - استدل المؤلف بالأحاديث والآثار لتقرير المسائل الفقهية المبثوثة في كتابه دون اشتراط صحتها، فيكون منها صحيحا وحسنا وضعيفا، بل منها ليس لها أصل وعدد يسير موضوع. ه - برزت شخصية أبي بكر الدمياطي الحديثية في كتابه (إعانة الطالبين) في نقاط تالية:

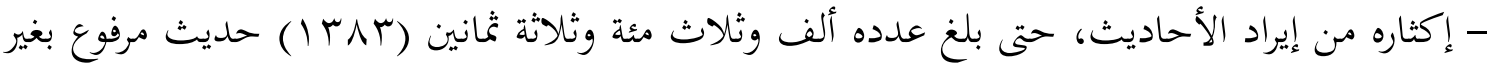
مكرر تقريبا -على حسب تقديري- استيعابه لعلم مصطلح الحديث، وظهر ذلك في كتاب (إعانة الطالبين). - اطلاعه على أحكام بعض العلماء على الحديث، فينقلها في كتابه. 7 - - تميز كتاب (إعانة الطالبين) بعنايته المتميزة بأحاديث الصحيحين في الاستدلال، حتى بلغ عددها في تقديري- ثلاثة وستون وخمسمئة (rاه) حديثا تقريبا، وهو عدد متميز يدل على عنايته بأحاديث الصحيحين. V - V من مناهج استدلال المؤلف بالحديث، عدم احتجاجه بالحديث الضعيف والمنكر، هذا وإن لم يكن منصوصا عليه في مقدمة كتابه، ولكن وقفنا على تصريهاته في ثنايا الكتاب، وهذا هو منهج سليم سديد يثنى عليه المؤلف. 1 - - يلاحظ على المؤلف، إيراده للأحاديث الضعيفة والموضوعة، ولعل عذره في صنيعه ما يلي: أن ذلك في فضائل الأعمال. أن ذلك بناء على ترجيحه في حكم على الحديث، أو بعبارة أخرى؛ أن الحديث صحيح عنده. أنه اختط منهج النقل في التأليف، دون الرجوع إلى المصادر الأصلية ولم يقم بدراسة الأسانيد، فوقع في الخطأ بناء على نقله. 


\section{البصيرة: مجلة الدراهات الإهلامية AL-BASSHIRAH: JOURNAL OF ISLAMIC STUIDES \\ Vol. 1 No. 1(2020): 1-20}

Website: https://journal.stiba.ac.id

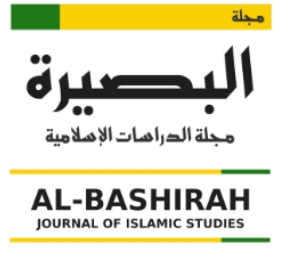

$$
\text { فهرس المراجع والمصادر }
$$

ا. الأحاديث الواردة في كتاب (إعانة الطالبين) للعلامة الدمياطي البكري الشافعي (من أول الكتاب إلى فهاية صلاة النفل) جمعا ودراسة، رسالة الماجستير بجامعة الملك سعود، إعداد الطالب: رشاد محمد سليم،

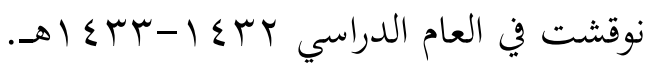

r. الأحاديث الواردة في كتاب (إعانة الطالبين) للعلامة الدمياطي البكري الشافعي (من بداية فصل في صلاة الجماعة إلى فاية أركان الصلاة على الميت) جمعا ودراسة، رسالة الماجستير بجامعة الملك سعود،

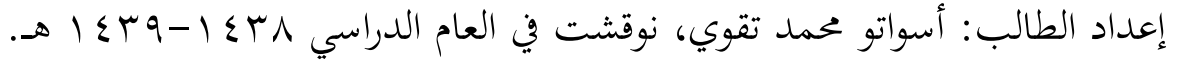
r. الأحاديث الواردة في كتاب (إعانة الطالبين) للعلامة الدمياطي البكري الشافعي (من بداية فصل شروط الصلاة على الميت إلى فاية ما يجب على على مؤخر قضاء الشيئ من رمضان) جمعا ودراسة، رسالة الماجستير بجامعة الملك سعود، إعداد الطالب: شفيق الرحمن ضياء الله ، نوقشت في العام الدراسي $\rightarrow 1 \leqslant r q-1 \leqslant r \wedge$

ع. الأحاديث الواردة في كتاب (إعانة الطالبين) للعلامة الدمياطي البكري الشافعي (من بداية فصل سنن الصيام إلى فماية فصل النذر) جمعا ودراسة، رسالة الماجستير بجامعة الملك سعود، إعداد الطالب: لقمان

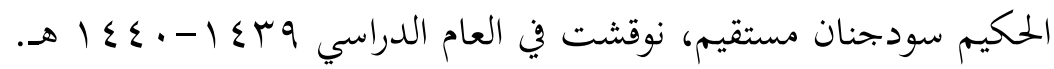
هـ الأحاديث الواردة في كتاب (إعانة الطالبين) للعلامة الدمياطي البكري الشافعي (من بداية كتاب النفقة إلى فاية الكتاب) جمعا ودراسة، رسالة الماجستير بجامعة الملك سعود، إعداد الطالب: أكبر علي شمس

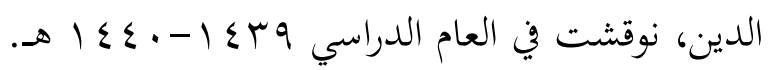

7. إعانة الطالبين على حل ألفاظ فتح المعين، أبو بكر محمد شطا الدمياطي، تحقيق: محمد عاشور، دار

$$
\text { إحياء التراث العربي، بيروت. }
$$

V. إعانة الطالبين على حل ألفاظ فتح المعين، أبو بكر محمد شطا الدمياطي، تحقيق: عبد الحكيم محمد عبد

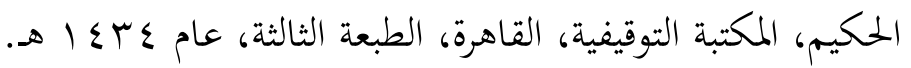

^. إعانة الطالبين على حل ألفاظ فتح المعين، أبو بكر محمد شطا الدمياطي، دار الفكر للطباعة والنشر والتوزيع، عام 11 إع إ هـ.

$$
\text { 9. الأعلام، خير الدين الزركلي، دار العلم للملايين، الطبعة: الخامسة عشر، عام ب . . Y م. }
$$

19 1 19 لقمان الحكيم سودهنان ,أبو بكر الدياطى الشافعى التعريف به وبيان منهجه الحديثى في كتابه (إعانة الطالبين) 


\section{البصيرة: مجلة الدراهات الإهلاهية AL-BASSHIRAH: JOURNAL OF ISLAMIC STUIDES \\ Vol. 1 No. 1(2020): 1-20}

Website: https://journal.stiba.ac.id

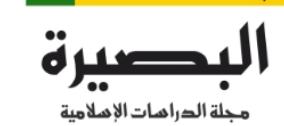

مجلة الصراهات الإهلاهية

AL-BASHIRAH

• 1 . أعلام المكيين من القرن التاسع إلى القرن الرابع عشر الهجري، عبد الله بن عبدالرحمن المعلمي،

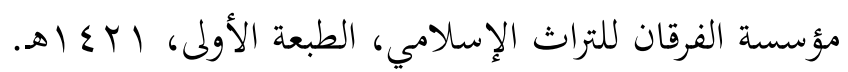

1 ا ـ . الحديث الضعيف وحكم الاحتجاج به، عبد الكريم بن عبد الله الخضير، مكتبة المنهاج بالرياض، الطبعة

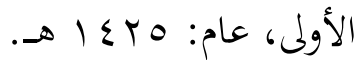

با. سير وتراجم بعض علمائنا في القرن الرارع عشر للهجرة، عمر عبد الجبار، التهامة، الطبعة الثالثة، ( ) ب

با. . فهرس الفهارس والأبنات ومعجم المعاجم والمشيخات والمسلسلات، لعبد الحي الكتاني، تحقيق:

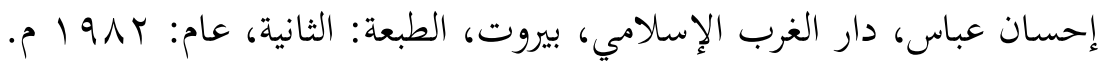
ع ا. المختصر من كتاب نشر النور والزهر في تراجم أفاضل مكة، الشيخ عبدالله مرداد أبو الخير،

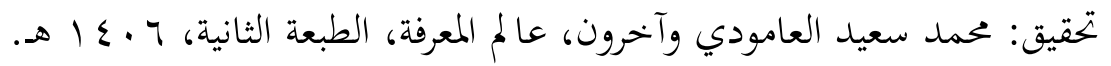

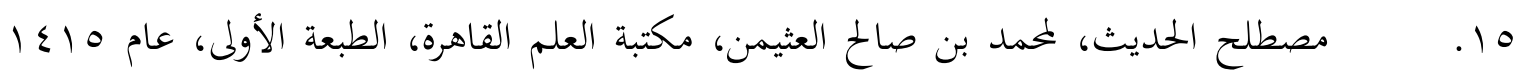
17 . معجم المطبوعات العربية والمعربة، ليوسف بن إليان بن موسى سركيس، مطبعة سركيس بمصر، عام

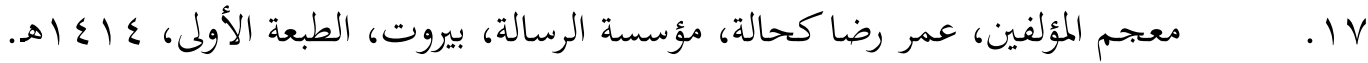
1 ا. ـ نثر الجواهر والدرر في علماء القرن الرابع عشر، يوسف المرعشلي، دار المعرفة، بيروت، الطبعة الأولى، . $) \leqslant Y V$ 19. هدية العارفين أسماء المؤلفين وآثار المصنفين، إسماعيل باشا البغدادي، دار إحياء التراث العربي،

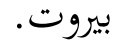

